NBER WORKING PAPER SERIES

\title{
THE USE OF LITERATURE BASED ELASTICITY ESTIMATES IN CALIBRATED MODELS OF TRADE-WAGE DECOMPOSITIONS: A CALIBMETRIC APPROACH
}

\author{
Hui Huang \\ John Whalley \\ Working Paper 10137 \\ http://www.nber.org/papers/w10137
NATIONAL BUREAU OF ECONOMIC RESEARCH
1050 Massachusetts Avenue
Cambridge, MA 02138 \\ December 2003
}

We are grateful to the Social Sciences and Humanities Research Council for support and to Shunming Zhang and Jim Davies and a seminar group at University of Western Ontario for comments. The views expressed herein are those of the authors and not necessarily those of the National Bureau of Economic Research.

(C)2003 by Hui Huang and John Whalley. All rights reserved. Short sections of text, not to exceed two paragraphs, may be quoted without explicit permission provided that full credit, including $(\mathrm{C}$ notice, is given to the source. 
The Use of Literature Based Elasticity Estimates in Calibrated Models of Trade-Wage Decompositions: A Calibmetric Approach

Hui Huang and John Whalley

NBER Working Paper No. 10137

December 2003

JEL No. C5

\begin{abstract}
How to best utilize the wide range of estimates of elasticities that characterize econometric literature when using calibrated models is the issue we address here through a blending of econometrics and calibration into calibmetrics. Econometrically generated literature based elasticity parameters are typically used in calibrated models a very simple manner, appealing to a single value. Here we explicitly incorporate the full range of values of elasticities yielded by econometric studies in both the calibration procedure employed and the uses made of a calibrated model. This is important because the ranges for such values can be large. This allows us to assess how uncertainty in exogenously specified parameter values affects the performance of calibrated models, and how much added information is obtained by using the full range of literature estimates of key parameters in calibration.

Hui Huang

Department of Economics

University of Western Ontario

London, ON N6A 5C2

Canada

hhuang@uwo.ca

John Whalley

Department of Economics

University of Western Ontario

London, ON N6A 5C2

Canada

and NBER

jwhalley@uwo.ca
\end{abstract}




\section{Introduction}

Much of the literature on calibration debates the relative merits of calibration and econometrics as if these were mutually exclusive choices. The papers in a symposium issue of the Journal of Economic Perspectives in 1996 all take this approach with papers by Sims (1996), Hansen and Heckman (1996), and Kydland and Prescott (1996). These and later contributions are summarized in Dawkins, Srinivasan, and Whalley (2001).

Here we take a different approach, arguing that calibrated models now occupy a central position in what is accepted in many circles as empirical work in economics and so the coexistence of econometrically estimated and calibrated models is the defacto situation. To us, the more realistic approach to calibration and econometrics seems to be to blend the two rather than argue their merits. We refer to this as calibmetrics.

In most calibration exercises elasticity parameters play a critical role since these are exogenously specified and econometric studies are typically appealed to justify the choices of parameter values. Usually, single values are used with some form of sensitivity analysis frequently employed. However, the reality is that for key elasticity parameters, such as for labour supply, capital labour substitution, intertemporal substitution, import demand, and others, the literature is characterized by wide ranges of estimates and even contrary signs for some estimates (see Killingsworth (1984), Piggott and Whalley (1985), Stern, Francis, and Schumacher (1976)). These differences in estimates occur for many reasons. Elasticity concepts differ across studies (compensated versus uncompensated, for instance), estimation methods differ, time periods vary, and sample sizes differ.

How to best utilize such a wide range of estimates in calibrated models is the issue we address here through calibmetrics. Our aim is to more fully explore the use of literature based econometrically generated elasticity parameters in calibrated models beyond what is typical in the literature. Our approach is to explicitly incorporate the full range of values of elasticities yielded by econometric studies in both the calibration procedure employed and the uses made of the calibrated model, asking how uncertainty in exogenously specified parameter values affects the performance of calibrated models.

Unfortunately the meaning of the term calibration varies from author to author and subarea to subarea. In microcalibrations, the roles of exogenous and endogenous variables are reversed with an equilibrium being treated as observed with calibration used simply 
to infer parameter values consistent with the observation. This typically requires data preadjustment since raw data do not meet the necessary equilibrium conditions of the model. In macrocalibrations parsimonious stochastic dynamic models are used which usually cannot be fitted exactly to data. Calibration in these cases then tries to obtain parameterizations for which model solutions are close to data, usually with little or no preadjustment to ensure full data admissibility to the equilibrium conditions in the model.

We use recent general equilibrium calibration and decomposition work due to Abrego and Whalley (2003) as the vehicle for our investigation. In this, these authors seek to evaluate the underlying causes of increases in the relative wage of skilled to unskilled labour in the UK between 1979 and 1995. Key elasticity values enter their calculations in a major way. Using UK data for both years they prespecify skilled-unskilled labour substitution elasticities in production and calibrate a two-period equilibrium structure so as to determine calibrated but data consistent rates of either skill or sector biased technical change. Between these years large differences in the ratio of skilled to unskilled wage rates are observed along with surges of imports of unskilled intensive goods and changes in the relative prices of unskilled and skilled intensive goods. The issue they address is how important each of these separate changes is in accounting for the observed total wage ratio change. Removing either technical change or relative price change from the second period equilibrium calculation allows them to decompose the influence of either on relative wage change using counterfactual equilibrium computation.

Abrego and Whalley adopt a procedure found in many other modeling efforts of using a single central tendency value, appealing to econometric literature estimates and citing a study by Hamermesh (1993) which reviews many studies of labour demand elasticities. This study includes a section on skilled unskilled labour substitution elasticities. While Abrego and Whalley use an elasticity estimate of 1.25, behind this is a key table in Hamermesh reporting 19 estimates. 5 of these are of the wrong sign, 1 is below 0.3 and 2 are above 5 . While 1.25 may be a defensible central tendency value for their purposes, how best to use this additional information in their model procedures is not clear, as also is whether one can make useful statements as to the likelihood of certain model outcomes in light of this range of estimates.

We focus on questions not addressed by Abrego and Whalley in our application here of calibmetrics. One is whether observations of large positive relative wage change for some 
economies (eg. US, UK) and close to zero for others (eg. Canada, France) can be consistent with the same model structure and only reflect parametric differences, or whether different structural models (such as those including unions, for instance) are needed to account for such observations. Another is how estimates of decompositions are affected by taking into account the full range of literature elasticity estimates.

We use a compendium of estimates of elasticities of skilled-unskilled labour substitution due to Hamermesh (1993) to infer the parameters of an assumed lognormal distribution (and later other distributions) of parameter estimates for the key Abrego-Whalley elasticity parameters (discarding all negative elasticity estimates). We then choose ranges around the wage change taken as observed in two economies, and using calibration and decomposition find the implied range of elasticities needed for any claimed contribution of international price change to observed wage change within the range. We then calculate the likelihood of the two target ranges of wage change occurring together, which we find to be small.

We also make a number of other calculations using the same approach. We assess the added information obtained by using a lognormal distribution compared to a uniform prior over a prespecified range of parameter values for these same calculations, implicitly asking what is the added value of using econometric estimates of elasticity parameters over an assumed range. We also grade and evaluate 14 estimates of substitution elasticities, showing how the use of various individual and subgroup estimates makes a substantial difference to model calculations of likelihood. We also use the same distributional approach to elasticity parameter specification to calculate likelihood values for the decompositions performed by Abrego and Whalley. We compare these to the decomposition results reported by Abrego and Whalley using this single central tendency elasticity estimate.

Our conclusion is that the ways in which elasticity parameters are used in calibrated models affects results in significant ways, in part because a wide range of estimated values exists in the literature and how one selects among these matters. While this conclusion may not seem surprising, the methods we exposit do, in our view, highlight the need for empirical work in economics to be as concerned with the numerical behaviour of analytical structures under different parameter settings as with more conventional hypothesis testing and forecasting. Calibmetrics represents this form of evolution in numerical simulation analysis. Here there is no hypothesis testing and no forecast, but the likelihood calculations produced are insightful for the subjective judgments on model choice that all empirical 
economists ultimately confront.

\section{Abrego and Whalley's Decomposition Experiments}

In their decomposition work Abrego and Whalley use a model of a small open, pricetaking economy calibrated to UK data for two years (1979 and 1995). During the period they study a substantial increase in wage inequality occurred in the UK with the relative wage of skilled to unskilled labour increasing by around $25 \%$. The issue they discuss is what portion of observed wage change can be attributed to import surges of low-wage goods which adversely affect unskilled labour and which to skill biased technical change. The UK, like other OECD countries, generally imports low-skill intensive goods and exports high-skill intensive goods.

They use a Ricardo-Viner specific-factors trade model with fixed factors in each of 2 sectors (skilled and unskilled labour intensive) as well as 2 sectorally fully mobile factors (skilled and unskilled labour). They use this model because for functional forms widely used for production, such as Cobb-Douglas or CES, Heckscher-Ohlin models (with homogeneous goods and constant returns to scale) have problems in accommodating relatively large product price changes due to the near linearity of the transformation frontier implied by the model (Abrego and Whalley, (2000)) and problems of complete specialisation following relative price changes ensue (Johnson, (1966)). Conventional Heckscher-Ohlin structures are also incapable of accommodating factor-biased technical change as a source of wage change for the small open economy case (Leamer, (1998); Krugman, (2000)).

\subsection{Production}

On the production side of the economy, they treat the UK as a small open price-taking economy that produces two goods, $M$ and $E$, both of which are traded at fixed world prices in period $t\left(P_{i t} ; i=M, E\right)$. The production of each good in each period requires the use of two mobile factors: skilled labour, $S$, and unskilled labour, $U$, along with a sector-specific fixed factor. Production, consumption and trade take place in each of the two time periods, 1 and 2, which they refer to as the initial and terminal periods.

Each good in each period is produced according to a decreasing returns to scale tech- 
nology:

$$
Y_{i t}=A_{i t} L_{i t}^{\alpha_{i t}}, \quad i=M, E ; \quad t=1,2
$$

where $Y_{i t}$ represents output of good $i$ in period $t, L_{i t}$ is the use of a composite labour input, and $A_{i t}$ denotes a sector-specific efficiency measure for a composite labour factor input. $a_{i t}$ is the elasticity of output with respect to composite labour, assumed to be strictly less than one to yield decreasing returns to scale.

The composite labour input in each sector, $L_{i t}$, is, in turn, a CES aggregate of skilled and unskilled labor, $S_{i t}$ and $U_{i t}$, used in sector $i$ in period $t$, i.e.

$$
L_{i t}=B_{i t}\left[\beta_{i t}\left(\delta_{t}^{U} U_{i t}\right)^{\frac{\sigma_{i t}-1}{\sigma_{i t}}}+\left(1-\beta_{i t}\right)\left(\delta_{t}^{S} S_{i t}\right)^{\frac{\sigma_{i t}-1}{\sigma_{i t}}}\right]^{\frac{\sigma_{i t}}{\sigma_{i t}-1}}, \quad i=M, E ; \quad t=1,2
$$

where $B_{i t}$ defines units for composite labor used in sector $i$ in period $t$, and $\beta_{i t}$ is the CES share parameter in the aggregation function. $\delta_{t}^{U}$ and $\delta_{t}^{S}$ are factor-augmenting technical change parameters which capture changes in input quality over time. $\sigma_{i t}$ denotes the elasticity of substitution between unskilled and skilled labour in sector $i$ in period $t$.

Combining (1) and (2) for each sector in each period yields

$$
Y_{i t}=\gamma_{i t}\left[\beta_{i t}\left(\delta_{t}^{U} U_{i t}\right)^{\frac{\sigma_{i t}-1}{\sigma_{i t}}}+\left(1-\beta_{i t}\right)\left(\delta_{t}^{S} S_{i t}\right)^{\frac{\sigma_{i t}-1}{\sigma_{i t}}}\right]^{\frac{\alpha_{i t} \sigma_{i t}}{\sigma_{i t}-1}}, \quad i=M, E ; \quad t=1,2
$$

where the units parameter in the consolidated function (3) $\gamma_{i t}=A_{i t} B_{i t}$. Consistent with the Ricardo-Viner approach, this production function implicitly defines a fixed factor in each sector with a Cobb-Douglas share of $\left(1-\alpha_{i t}\right)$. In $(3)$, changes in $\gamma_{i t}$ represent sectorspecific, Hicks-neutral technical change, while $\delta_{t}^{U}$ and $\delta_{t}^{S}$ determine factor-biased technical change. In the empirical implementation of their model, Abrego and Whalley assume that production of $M$, the importable good, is intensive in unskilled labour in both periods, i.e. $\beta_{M t}>\beta_{E t}, \forall t$ (as is the case in most OECD economies).

\subsection{Labour Markets}

Competitive labour markets are assumed with each type of labour paid its marginal value product and full employment of each type of labour in each period. The endowments of skilled and unskilled labour are assumed to be fixed in each time period at $\bar{S}_{t}$ and $\bar{U}_{t}$ respectively, while varying across periods. 
First order conditions for factor demands implied by marginal product pricing are

$$
W_{U t}=\frac{P_{i t} \alpha_{i t} \beta_{i t} \delta_{U t}^{\frac{\sigma_{i t}-1}{\sigma_{i t}}} Y_{i t}^{\frac{\sigma_{i t}\left(\alpha_{i t}-1\right)+1}{\sigma_{i t}-1}}}{U_{i t}^{\frac{1}{\sigma_{i t}}} \gamma_{i t}^{\frac{\alpha_{i t} \sigma_{i t}-1}{\sigma_{i t}-1}}}, \quad i=M, E ; \quad t=1,2
$$

and

$$
W_{S t}=\frac{P_{i t} \alpha_{i t}\left(1-\beta_{i t}\right) \delta_{S t}^{\frac{\sigma_{i t}-1}{\sigma_{i t}}} Y_{i t}^{\frac{\sigma_{i t}\left(\alpha_{i t}-1\right)+1}{\sigma_{i t}-1}}}{S_{i t}^{\frac{1}{\sigma_{i t}}} \gamma_{i t}^{\frac{\alpha_{i t} \sigma_{i t}}{\sigma_{i t}-1}}}, \quad i=M, E ; \quad t=1,2 .
$$

where $W_{U t}$ and $W_{S t}$ denote unskilled and skilled wage rates in period $t$, and $P_{i t}$ are the (fixed) world prices for good $i$ in period $t$. Given the decreasing returns technology set out in (1), payments to skilled and unskilled labour do not exhaust the value of production in each sector. The remaining factor income in the period implied by (1) accrues to the fixed factor in the relevant sector.

\subsection{Trade and Trade Shocks}

Imports and competitive domestically produced goods are treated as homogeneous in the model, with a similar treatment used for exportables. This homogeneity assumption implies that trade flows for any good are always one-way, and that one of the goods is exported and the other imported. In equilibrium a zero trade balance condition holds, i.e.

$$
\Sigma_{i=M, E} P_{i t} T_{i t}=0
$$

where $T_{i t}$ denotes the net trade of the country (import/export) in the two goods in the period, $M_{i t}$ and $E_{i t}$. If good $i$ is exported, domestic production less consumption, $T_{i t}$ is positive; if good $i$ is imported, $T_{i t}$ is negative.

Trade shocks are modeled as changes in world prices which typically induce increased imports. The shock Abrego and Whalley consider for the UK between 1979 and 1995 is a fall in the relative price of unskilled intensive to skill intensive goods between the two years. These generate larger imports, adjustment of labour out of the unskilled intensive sector, and increases in exports of skilled-intensive goods.

\subsection{Equilibrium}

Given the small open economy assumption used in the model, goods markets do not clear domestically since they are but part of integrated world markets. Imports and exports reflect 
positive and negative excess demands which are absorbed or met by world markets (subject to trade balance). The UK, as a small economy, thus faces perfectly elastic demands and supplies at the fixed world prices.

In the model, equilibrium in each period is given by unskilled and skilled wage rates such that each of the two domestic labour markets clear. The value marginal product of each type of labour in each sector is equal to the corresponding wage (as in (4) and (5)), and the fixed factor in each sector $i$ receives the residual return, $F_{i t}$, in period $t$.

Market clearing conditions for each labour market hold in both periods, with skilled and unskilled wage rates $W_{U t}$ and $W_{S t}$ determined such that

$$
\Sigma_{i} U_{i t}=\bar{U}_{t}, \quad i=M, E ; \quad t=1,2 .
$$

and

$$
\Sigma_{i} S_{i t}=\bar{S}_{t}, \quad i=M, E ; \quad t=1,2 .
$$

The fixed factor in each sector receives the difference between the value of production at world prices and payments to the two types of labour. This enters incomes which, in turn, finance demands.

Consumption of each good is given by the difference between production and net trade, i.e.

$$
C_{i t}=Y_{i t}-T_{i t}, \quad i=M, E ; \quad t=1,2 .
$$

where $C_{i t}$ denotes consumption of good $i$ in period $t$. A property of equilibrium in such a model (from Walras Law) is that trade balance holds.

\subsection{Model Calibration and Decomposition Experiments}

Abrego and Whalley's calibration of this model structure to 1979 and 1995 UK data consists of choosing values for model parameters such that the model gives equilibrium solutions which are consistent as far as possible with observed data in both periods. In the small open economy case, behaviour on the demand and production sides of the model is independent in the sense that once optimizing decisions are made on the production side of the economy incomes are determined, and (given world prices) demands on the consumption side are determined. Since the focus of their decomposition is on determinants of wage rate change, demand side considerations are not involved (nor are there statements made about 
consumer welfare). This independence feature allows Abrego and Whalley to concentrate only on the production side when calibrating their model.

The decompositional focus in Abrego and Whalley is to better understand the significance of factors behind ex-post changes in key variables (skilled and unskilled wage rates). Calibration in micro-based models used to evaluate policy options on an ex-ante basis usually occurs in so called levels form to a single, model-consistent equilibrium data set constructed from observed outcomes (see Dawkins, Srinivasan, and Whalley (2000)). The data used in these procedures are typically constructed from basic data which frequently violate the model equilibrium conditions. They are typically modified for model compatibility through a series of subjective judgment driven modifications to yield a benchmark equilibrium model admissible data set (see Shoven and Whalley, (1992)). Abrego and Whalley's aim is to use a calibration which is consistent with data in both periods, and which captures these changes in variables over time that are at the heart of their analysis. It thus involves two data observations rather than one as in more conventional micro based calibration.

It is usual in single period calibrations to assume that the values of elasticities of substitution in production $(\sigma)$ are exogenously given, with the values chosen based on literaturebased estimates of the relevant parameters. They use a single substitution elasticity parameter value between skilled and unskilled labour for both the sectors of 1.25 , appealing to Hamermesh's (1993) literature survey of econometric estimates. They explore how changes in this parameter value(from 0.75 to 2.5 ) affect their results through sensitivity analysis.

Abrego and Whalley's assumed values for both periods leave sixteen production-side parameter values in their model to be determined through calibration. These are output elasticities with respect to composite labour, units terms in sector production functions, CES shares in aggregation functions, and factor biased technological change parameters, i.e.

$$
\alpha_{i t}, \gamma_{i t}, \beta_{i t}, \delta_{t}^{U}, \delta_{t}^{S} ; \quad i=M, E ; \quad t=1,2
$$

For these parameters to be consistent with the model equilibrium conditions in each time period, the values determined must satisfy the first order conditions (4) and (5), as well as equation (3). This yields a system of 12 equations in 16 unknowns, and additional restrictions are needed to determine parameter values using this system. 
Abrego and Whalley first set

$$
\delta_{1}^{U}=\delta_{1}^{S}=1
$$

which they interpret as a normalization rule for factor-biased technological change.

They then impose further restrictions on model parameterizations to yield an equation system for calibration across the two time periods in which the remaining endogenous model parameters are exactly identified. They use three alternative sets of restrictions, each of which yields an exactly identified system from which parameter values for the model can be determined.

These are

$$
\begin{array}{ll}
\text { Restriction } 1 & \delta_{t}^{U}=\delta_{t}^{S}=1 \\
\text { Restriction } 2 & \gamma_{i 1}=\gamma_{i 2}, \quad i=M, E
\end{array}
$$

or

$$
\text { Restriction } 3 \quad \beta_{i 1}=\beta_{i 2}, \quad i=M, E
$$

Restriction 1 implies that no factor-biased technical change occurs over time. Restriction 2 implies that no Hicksian-neutral technical change takes place over time. Restriction 3 allows technical change to be both Hicks-neutral and factor-biased, but rules out any change over time in share parameters in the composite CES labour aggregation function. These three alternatives differ in their implied treatment of technical change over time. Abrego and Whalley do not restrict their choice of $\alpha_{i t}$ when implementing calibration since these parameter values determine the share of composite labour input in sectoral income, and must be consistent with the shares implied by the data used for each time period.

Using each of these sets of restrictions, they are able to calibrate their model and then assess the implications of each for their decomposition results. They use their model (calibrated in each of the three ways set out above) to generate estimates of the contribution of increased trade, factor-biased technical change, and also factor endowment change (demographics) to changes in UK wage inequality between 1979 and 1995. All the changes in model parameters taken together are consistent with observed wage inequality change as well as with other characteristics of the observed period 2 equilibrium. They capture trade shocks in their analysis as changes in world prices (the relative price of skill intensive to unskilled intensive goods facing the UK in international markets between 1979 and 1995). 
These shocks affect trade flows, which are endogenously determined in the model. Factorbiased technical change is modeled as changes in the technical change parameters $\delta_{t}^{U}$ and $\delta_{t}^{S}$

For each model parameterization generated by the three alternative calibrations set out above, they assess the contribution of each component to changes in wage inequality. They do this by first taking the equilibrium of period 1 as the base, and then resolving the model for the second period only including the trade shock. This permits a calculation of the portion of the observed two-period change in wage inequality which can be attributed to the trade shock. They can also accommodate the various restrictions implied by each of the technology parameter changes implied by each of the calibration procedures they use and repeat their procedures. They also assess the impacts of changes in factor endowments on inequality in a similar manner.

The proportions of the total change in wage inequality between the two years attributed in this way to each component need not (and typically will not) sum to the total change in wage inequality actually observed. Each experiment only considers a change in a subset of three exogenous variables, and these have interacting effects which imply that their separate contributions may sum to more or less than the observed wage inequality change. The quantitative significance of this non-additivity property is something revealed by numerical computation.

Abrego and Whalley conclude from their calculations that the contribution of trade shocks to observed increases in wage inequality in the UK is relatively small, but also that the calibration procedures used affect results. 


\section{Calibmetrics, Elasticity Parameters, Country Comparisons of Relative Wage Change, and Likelihood Results for De- compositions}

The first of our applications of calibmetrics reported on here using the Abrego-Whalley approach focuses on elasticity parameters and the cross country feature noted in some of the trade and wages literature that there is different behaviour of the relative skilled to unskilled wage rate across countries even where the same international shocks seemingly apply to individual economies. An example is the difference between the US and Canada. In the US the relative wage change has been in the order of $25 \%$ (see Slaughter (1999)) while in Canada there have been small to zero change in the relative wage of skilled to unskilled labour over the last decades (see Murphy, Riddell and Romer (1998)). Similar experiences apply for the different outcomes across European countries, between the UK and France for instance.

If two economies are subject to the same international price shocks, and if technical change flows equally across national borders, there is seemingly a puzzle as to how this could happen. One hypothesis is that the two economies at issue can be represented by the same model structure, but parameter values differ between the economies and hence a different outcome is observed. Another is that different structural models are needed for the two economies to account for the different empirical observations. For instance, it may be that a model of Canada that explicitly incorporates, say, resource rents or labour unions is helpful instead in accounting for differences relative to US experience.

In applying calibmetrics to explore the possible consistency of different outcomes from a common model to two countries with differences in parametric values used in the same model structure, we note the key role played by elasticities of skilled-unskilled labour substitution in the Abrego-Whalley calculations, and the large range of elasticity estimates in the key table from Hamermesh (1993) on which they draw.

This table is reproduced here as Table 1 , from which it can be seen that in reality there is a wide range of elasticity estimates; not the single value used by Abrego and Whalley. As can be seen there are differences in sign and also large differences in size of estimates across studies. Most estimates are for the US, some are for all manufacturing others for 
particular industries. Some use duality (translog) approaches, some directly estimate a production function. Given the range of values reported in Table 1, which estimates to use in a calibrated model and why is the issue. Abrego and Whalley suggest in their paper that this table loosely supports use of a value of 1.25 and use a single value for both sectors in their model and make their decompositional calculations on this basis.

Table 1. Hamermesh (1993) Estimates of Substitution $(\sigma)$ Between Skilled and Unskilled Workers ${ }^{1}$

\begin{tabular}{|l|l|c|}
\hline Study & Description & $\sigma$ \\
\hline Dougherty (1972) & $\begin{array}{l}\text { All industry, US states, 1960; } \\
\text { multilevel CES, 8 occupation groups }\end{array}$ & 4.1 \\
\hline Chiswick (1979) & $\begin{array}{l}\text { US States, manufacturing, 1910, 1920; } \\
\text { professional, others; CES }\end{array}$ & 2.5 \\
\hline Kesselman, Williamson, & $\begin{array}{l}\text { US Manufacturing annual 1962-71; } \\
\text { KBW, translog cost }\end{array}$ & 0.49 \\
\hline Clark and Freeman (1977) & $\begin{array}{l}\text { US Manufacturing, annual, 1950-76; } \\
\text { KBW, translog cost }\end{array}$ & 0.91 \\
\hline Berndt and White (1978) & $\begin{array}{l}\text { US Manufacturing, annual, 1947-71; } \\
\text { KBW, translog cost }\end{array}$ & 3.70 \\
\hline Dennis and Smith (1978) & $\begin{array}{l}\text { 2-digital US manufacturing, annual, 1952-73; } \\
\text { KBW, money balances; translong cost }\end{array}$ & -0.05 \\
\hline Grant (1979) & $\begin{array}{l}\text { US SMSAs, 1970; KB, 2 white-collar; translog } \\
\text { cost. Professional, managers }\end{array}$ & 0.62 \\
\hline Frant (1979) & $\begin{array}{l}\text { US SMSAs, 1970; KB, 2 white-collar; translog } \\
\text { cost. Sales, clericals }\end{array}$ & 0.14 \\
\hline 2-digit manufacturing, US states, 1972; \\
KBW; translog cost: Union \\
2-digit manufacturing, US states, 1972; \\
KBW; translog cost: Nonnion
\end{tabular}

\footnotetext{
${ }^{1}$ Source: Hamermesh (1993) Table 3.7, P.110-111
} 
Table 1. (Continued)

\begin{tabular}{|l|l|c|}
\hline Study & Description & $\sigma$ \\
\hline Berger (1984) & $\begin{array}{l}\text { 2-digit manufacturing, US states, annual, } \\
\text { 1971-77; KBWE prices, translong cost }\end{array}$ & $<0$ \\
\hline Turnovsky and Donnelly (1984) & $\begin{array}{l}\text { Iron and steel, annual, 1959-79; } \\
\text { Australia, translong cost: KBWEM }\end{array}$ & -0.48 \\
\hline Turnovsky and Donnelly (1984) & $\begin{array}{l}\text { Iron and steel, annual, 1959-79; } \\
\text { Australia, translong cost: KBWE }\end{array}$ & -0.04 \\
\hline Bergstrom and Panas (1992) & $\begin{array}{l}\text { 2-digit manufacturing, annual, 1963- } \\
\text { 80; Sweden; K, salaried, wage earners, } \\
\text { translog cost }\end{array}$ & 1.20 \\
\hline Berndt and Christensen (1974) & $\begin{array}{l}\text { US Manufacturing, annual, 1929-68 } \\
\text { KBW translog production }\end{array}$ & 5.51 \\
\hline Denny and Fuss (1977) & $\begin{array}{l}\text { US Manufacturing, annual, 1929-68; BW, } \\
\text { equipment, structures, translog production }\end{array}$ & 4.76 \\
\hline Klotz, Madoo, and Hanson (1980) & $\begin{array}{l}\text { US Manufacturing, annual, 1929-68; BW, } \\
\text { translog production. lowest quartile plants }\end{array}$ & 2.06 \\
\hline Klotz, Madoo, and Hanson (1980) & $\begin{array}{l}\text { equipment, structures, translog cost } \\
\text { translog production. highest quartile plants }\end{array}$ & 6.00 \\
\hline
\end{tabular}


We first modify the Abrego-Whalley procedures by utilizing the full range of the elasticity estimates reported in Hamermesh (1993) while maintaining their assumption that the same common value applies to each of the two sectors in their UK model. We ask what is the likelihood of observing two different country outcomes for relative wage change given both common price and technology shocks and the range of elasticity estimates in Table 1. We then make calculations of the likelihood of observing different wage changes across economies using the same structural model as common to two economies but with differences allowed in elasticity parameter values. To do this we calibrate the model to the same base case data for the UK and then use different elasticity values for the common skilled-unskilled labour substitution elasticity parameter in place of the value used in the original calibration. In each case we calculate the implied wage rate change for a common price shock.

We begin from the model specification used by Abrego and Whalley and the parameter values generated by their first calibration procedure using an elasticity value of 1.25 . We then construct a density function, $f(\sigma)$, over the common elasticity value used in the two sectors using the range implied by the literature estimates in Table 1 . We first use a lognormal distribution with the mean and variance of this distribution calculated from Table 1, discarding all elasticity estimates of the wrong sign and letting the range be nonnegative.

We then adopt target values for wage change in two economies of $0 \%$ and $25 \%$ and use the same UK data and non-elasticity calibrated parameters as Abrego and Whalley to explore whether these ranges apply. This enables us to calculate the density for $0 \%$ and $25 \%$ wage changes for given ranges around these target values. We use $\pm 2.5 \%$ and $\pm 5 \%$ as our ranges. $0 \%$ and $25 \%$ are not the precise values characterizing observed wage changes in two actual economies, but are roughly reflecting of the differences in the 1980's and 90's between the UK and France. Our likelihood estimates are set out in Table 2, which show small estimates to be involved. These suggest that the likelihood that different observations of wage change across two economies (UK and France) could be consistent with the same structural model, but different values of the elasticity of substitution between skilled and unskilled labour compatible with the distribution of literature estimates is small. Seemingly, the more plausible position is to argue that different structural models (such as with and without unions) are a more satisfactory way to accomodate the phenomenon observed. 
Table 2. Assessing the Likelihood of Observing Different Joint Wage

Change across 2 Countries Using the Same Structural Model in which Only Substitution Elasticities Parameters Vary

\begin{tabular}{|c|c|c|}
\hline \multicolumn{3}{|l|}{ A. Experiment } \\
\hline \multicolumn{3}{|c|}{$\begin{array}{l}\text { - Target wage change for } 2 \text { economies selected for UK model } \\
\text { double calibrated (using procedure } 1 \text { above) to } 1979 \text { and } \\
1995 \text { data } \\
\text { - Specify range around targets (see below) } \\
\text { - Use non-negative literature estimates of } \sigma \text { to construct } \\
\text { lognormal } f(\sigma) \\
\text { - Calculate joint density for two country wage changes given } \\
\text { the above }\end{array}$} \\
\hline \multicolumn{3}{|c|}{ B. Likelihood Results (Targets for wage change $(0 \%, 25 \%)$ ) } \\
\hline & Range & change \\
\hline & $\pm 2.5 \%$ & $\pm 5.0 \%$ \\
\hline Density $^{2}$ for $0 \%$ wage change & 0.023 & 0.047 \\
\hline Density $^{2}$ for $25 \%$ wage change & 0.101 & 0.210 \\
\hline Implied joint density ${ }^{2}$ (likelihood) & 0.002 & 0.010 \\
\hline
\end{tabular}

${ }^{2}$ These are the portion of a total density of unity.

In Table 3 we use alternative uniform density functions to investigate the sensitivity of the results in Table 2. We use a range of values of $\sigma$ given by their minimum and maximum values reported in Table 1 . We assume a uniform density function instead of the lognormal distribution used above. The calculated likelihood estimates change substantially (by a factor of approximately 3 ) when the form of density functions used is varied. These are considerably lower in the uniform density case, since the target values of $0 \%$ and $25 \%$ change are concentrated in regions of the lognormal density functions with large mass. We interpret these calculations as providing an assessment of how the full distribution 
of literature estimates of elasticity parameter values can change or inform estimates of likelihood of observing joint wage outcomes across two economies using the same structural model.

Table 3. Sensitivity of Likelihood Calculations to Assumed Density Function for $\sigma$ of Joint Observed Wage Change

\begin{tabular}{|c|c|c|c|c|}
\hline \multicolumn{5}{|l|}{ A. Experiment } \\
\hline \multicolumn{5}{|c|}{$\begin{array}{l}\text { - Same as Table } 2 \\
\text { - Now repeated for uni } \\
\text { a prespecified range }\end{array}$} \\
\hline \multicolumn{5}{|c|}{ B. Results (Targets for wage change $(0 \%, 25 \%))$} \\
\hline & \multicolumn{4}{|c|}{ Range of wage change } \\
\hline & \multicolumn{2}{|c|}{ $\pm 2.5 \%$} & \multicolumn{2}{|c|}{ $\pm 5.0 \%$} \\
\hline & $\begin{array}{l}\text { literature } \\
\text { based } f(\sigma) \\
(\text { table } 2)\end{array}$ & $\begin{array}{l}\text { uniform density } \\
\qquad f(\sigma) \text { over } \\
\text { min/max range }\end{array}$ & $\begin{array}{l}\text { literature } \\
\text { based } f(\sigma) \\
\text { (table } 2)\end{array}$ & $\begin{array}{l}\text { uniform density } \\
\qquad f(\sigma) \text { over } \\
\text { min/max range }\end{array}$ \\
\hline $\begin{array}{l}\text { Density }^{2} \text { for } \\
0 \% \text { wage change }\end{array}$ & 0.023 & 0.010 & 0.047 & 0.020 \\
\hline $\begin{array}{l}\text { Density }^{2} \text { for } \\
25 \% \text { wage change }\end{array}$ & 0.101 & 0.067 & 0.210 & 0.150 \\
\hline $\begin{array}{l}\text { Implied joint } \\
\text { density }^{2} \text { (likelihood) }\end{array}$ & 0.002 & 0.001 & 0.009 & 0.003 \\
\hline
\end{tabular}

${ }^{2}$ These are the portion of a total density of unity. 
Table 4 reports the sensitivity of likelihood calculations of joint wage change over target ranges to alternative specifications of the experiments and changes made in implementing calculations. We both change the range of the uniform density function assumed, and vary the target for wage change in one the countries as well as use alternatives to the lognormal distribution. Likelihood calculations for joint wage change within target ranges change again and by even larger amounts than in Table 3, with estimates spanning a range of 5:1. They still remain small, however.

Table 4. Sensitivity of Likelihood Calculations of Joint Wage Change to Experiment Implementation Procedures

\begin{tabular}{|c|c|c|c|c|}
\hline \multicolumn{5}{|l|}{ A. Experiment } \\
\hline \multicolumn{5}{|l|}{ - Same as Table 2} \\
\hline \multicolumn{5}{|c|}{ B. Results For Implied Joint Density ${ }^{2}$} \\
\hline & \multicolumn{4}{|c|}{ Range of wage change } \\
\hline & \multicolumn{2}{|c|}{ $\pm 2.5 \%$} & \multicolumn{2}{|c|}{ $\pm 5.0 \%$} \\
\hline & $\begin{array}{c}\text { literature } \\
\text { based } f(\sigma) \\
\text { (table } 2)\end{array}$ & $\begin{array}{l}\text { uniform density } \\
\qquad f(\sigma) \text { over } \\
\text { min/max range }\end{array}$ & $\begin{array}{l}\text { literature } \\
\text { based } f(\sigma) \\
\text { (table } 2)\end{array}$ & $\begin{array}{l}\text { uniform density } \\
\qquad f(\sigma) \text { over } \\
\text { min/max range }\end{array}$ \\
\hline Table 3 (above) & 0.0023 & 0.0006 & 0.0098 & 0.0030 \\
\hline $\begin{array}{l}\text { Min } / \text { max range in un- } \\
\text { iform density } 2 \text { replaced } \\
\text { by } 2 \times \min / 2 \times \max \end{array}$ & 0.0023 & 0.0002 & 0.0098 & 0.0008 \\
\hline $\begin{array}{l}\text { Density }{ }^{2} \text { when Targets } \\
\text { changed to }(10 \%, 25 \%)\end{array}$ & 0.0037 & 0.0012 & 0.0158 & 0.0053 \\
\hline
\end{tabular}

${ }^{2}$ These are the portion of a total density of unity. 
Table 5 considers the impacts of variations on the calibration procedures used on joint wage likelihood calculations, modifying these from procedure 1 in Abrego and Whalley to their procedures 2 and 3 discussed above. The proportional size of variation in estimates between lognormal and uniform distribution enlarges as different procedures are used, again suggesting differences in results across procedures but also indicating how these different procedures can be implemented. These results suggest that choice of calibration method may be more important for estimates of joint likelihood than the choice of $\sigma$, as conventional calibration literature focuses on. In turn, the wider implication is that a range of characteristics and procedures beyond simple parameter selection affect the outcomes generated by calibrated models, a point not currently recognized in literature.

Table 5. Sensitivity of Likelihood Calculations of Joint

Wage Change to Calibration Procedures

\begin{tabular}{|c|c|c|c|c|}
\hline \multicolumn{5}{|l|}{ A. Experiment } \\
\hline \multicolumn{5}{|l|}{ - Same as Table 2} \\
\hline \multicolumn{5}{|c|}{ B. Results For Implied Joint Density ${ }^{2}$} \\
\hline \multirow[b]{3}{*}{ Implied Joint Density ${ }^{2}$} & \multicolumn{4}{|c|}{ Range of wage change } \\
\hline & \multicolumn{2}{|c|}{ $\pm 2.5 \%$} & \multicolumn{2}{|c|}{ $\pm 5.0 \%$} \\
\hline & $\begin{array}{c}\text { literature } \\
\text { based } f(\sigma) \\
\text { (table } 2)\end{array}$ & $\begin{array}{l}\text { uniform density } \\
\qquad f(\sigma) \text { over } \\
\text { min/max range }\end{array}$ & $\begin{array}{c}\text { literature } \\
\text { based } f(\sigma) \\
\text { (table } 2)\end{array}$ & $\begin{array}{l}\text { uniform density } \\
\qquad f(\sigma) \text { over } \\
\text { min/max range }\end{array}$ \\
\hline Table 3 (above) & 0.0023 & 0.0007 & 0.0098 & 0.0030 \\
\hline $\begin{array}{l}\text { Use of Calibration } \\
\text { method } 2(\text { not } 1)\end{array}$ & 0.0006 & 0.0002 & 0.0025 & 0.0008 \\
\hline $\begin{array}{l}\text { Use of Calibration } \\
\text { method } 3 \text { (not } 1)\end{array}$ & 0.0001 & 0.00002 & 0.0003 & 0.0001 \\
\hline
\end{tabular}

${ }^{2}$ These are the portion of a total density of unity. 
Table 6 reports the sensitivity of the likelihood calculations made above to the value used as the central tendency elasticity estimate extracted from the literature in both sectors in the original Abrego-Whalley procedure. We report on different procedures for obtaining a single value in the Table and show the implications for calculations of likelihood of joint wage change. Results are sensitive to the choice of value, highlighting the key role played by judgment in implementing calibration procedures through the choice of elasticity parameter values. The degree of sensitivity, however, is considerably less than that shown for other characteristic of calibration procedure (see table 5 ).

Table 6. Sensitivity of Likelihood Calculations of Joint Wage Change to Methods Used to Survey Literature Elasticities to Produce an Initial Central Tendency Estimate

\begin{tabular}{|l|c|c|}
\hline $\begin{array}{l}\text { Alternative Methods } \\
\text { ermesh Estimates }\end{array}$ & $\begin{array}{c}\text { Implied Elasticity } \\
\text { Value for skilled- } \\
\text { unskilled substitution }\end{array}$ & $\begin{array}{c}\text { Likelihood (implied joint density }{ }^{2} \text { ) } \\
\text { of observing joint (0\%, 25\%) } \\
\text { wage change with interval of } \pm 2.5 \%\end{array}$ \\
\hline As in Abrego-Whalley & 1.25 & 0.0023 \\
\hline $\begin{array}{l}\text { Simple average of all } \\
\text { estimates }\end{array}$ & 1.898 & 0.0051 \\
\hline $\begin{array}{l}\text { Drop all negative } \\
\text { elasticity estimates } \\
\text { from average }\end{array}$ & 2.482 & 0.0073 \\
\hline $\begin{array}{l}\text { Average of translog } \\
\text { cost function estimates }\end{array}$ & 0.774 & 0.0007 \\
\hline Average of CES estimates & 3.3 & 0.0099 \\
\hline $\begin{array}{l}\text { Average of only US } \\
\text { estimates }\end{array}$ & 1.969 & 0.0054 \\
\hline $\begin{array}{l}\text { Averaged estimates using } \\
\text { annual times series data }\end{array}$ & 1.806 & 0.0047 \\
\hline
\end{tabular}

${ }^{2}$ These are the portion of a total density of unity. 
Finally, we assess the sensitivity of the Abrego-Whalley decomposition estimates themselves to the use of the full range of skilled-unskilled elasticity estimates in the Hamermesh study rather than only use a single central tendency value. To do this we approximate the lognormal density function $f(\sigma)$ by a sense of piecewise linear segments, and for the central value of each range we repeat the Abrego-Whalley decomposition. We then use the density of each range to produce expected values for decomposition results. These are reported in Table 7. These show some degrees of sensitivity of results to the procedure used but the impacts are small. Interestingly, while using the full range of $\sigma$ values from econometric literature in calculations of joint likelihood of wage change seems to make a large difference, for the decomposition results themselves as reported by Abrego and Whalley the impacts seem small. This highlights how calibmetrics as a procedure and approach will both vary from question to question, and yield different insights. In an assessment of how important it is to use the full range of literature estimates for key parameters in calibrated models here it matters for reconciling joint economy outcomes with model structures but for decomposition results it appears not play such a large role.

Table 7. Sensitivity of Abrego-Whalley Trade-Wage Decomposition to the Use of Fall Range of Literature Elasticity Values in Distribution From

\begin{tabular}{|l|c|c|}
\hline & $\begin{array}{c}\text { Original Abrego-Whalley } \\
\text { decompositions showing } \\
\text { relative importance of } \\
\text { factors in observed UK } \\
\text { wage change } 1979-1995\end{array}$ & $\begin{array}{c}\text { Procedures repeated } \\
\text { for piecewise linear } \\
\text { approximation of } f(\sigma) \\
\text { and combined to yield } \\
\text { expected value }\end{array}$ \\
\hline Increased trade & $17 \%$ & $19 \%$ \\
\hline Factor-biased technical change & 0 & 0 \\
\hline Hicks-neutral technical change & $1 \%$ & $-4 \%$ \\
\hline Factor endowment changes & $-144 \%$ & $-183 \%$ \\
\hline Changes in $\beta_{i t}$ & $183 \%$ & $189 \%$ \\
\hline Changes in $\alpha_{i t}$ & $-19 \%$ & $-22 \%$ \\
\hline
\end{tabular}




\section{Concluding Remarks}

This paper presents procedures for combining the typically wide range of econometrically generated estimates of key elasticity parameter values used in calibrated models with the implementation procedures actually used in calibration and counterfactual calculations. We term our approach calibmetrics, reflecting a blending of econometrics and calibration in light of the defacto situations of calibrated models relying on literature estimates of parameter values selected from often disparate econometric estimates. We emphasize the inevitable need for subjective judgement in all numerical (or empirical) work in economics including in econometrics. Here the issues are what difference it makes to use the full and typically wide rage of econometric estimates of key parameters when using calibrated models.

We draw on a study of the UK of trade effects on relative skilled and unskilled wage rates due to Abrego and Whalley using data for 1979 and 1995 which utilizes a single elasticity parameter value for te elasticity of substitutions between skilled and unskilled labour loosely justified by appealing to a literature compendium produced by Hamermesh (1993). Abrego and Whalley use a single value of 1.25, even though Hamermesh reports 19 values which range from negative to over 5 . We show how it is possible to use calibration methods so as to incorporate the full range of elasticity estimates produced by Hamermesh in distributional form. We use a range of procedures to explore the likelihood of model observations of joint wage changes across economies, using a similar parameter specification for a common model using the full variation in elasticity parameters across economies. We also assess the implications for decompositional analysis for each of a number of underlying factors driving changes in relative skilled-unskilled wage changes over time. Calibmetric results are sensitive to the procedures used, and using the full range of literature estimates changes the model results significantly. Interestingly, using the full range of calibmetrically generated estimates seems to make large difference to likelihood calculations but only a small difference to decomposition results. 


\section{References}

[1] Abrego, L. and J.Whalley (2000) The Choice of Structural Model in Trade-Wages Decompositions. Review of International Economics, 8, 462-77.

[2] Abrego, L. and J.Whalley (2003) Decomposing Wage Inequality Change Using General Equilibrium Models. Forthcoming in ed. T.J.Kehoe, T.N.Srinivasan, and J.Whalley, New Frontier in Equilibrium Modelling, Cambridge University Press.

[3] Dawkins, C., T.N.Srinivasan, and J.Whalley (2000) Calibration in ed. E.C.Leamer and J. Heckman, Handbook of Econometrics, North-Holland.

[4] Hamermesh, D.S. (1993) Labor Demand. Princeton, N.J: Princeton University Press.

[5] Hansen, L.P. and J.J.Heckman (1996) The Empirical Foundations of Calibration. Journal of Economic Perspectives, 10, 87-89.

[6] Johnson, H.G. (1966) Factor Market Distortions and the Shape of the Transformation Frontier. Econometrica, 34, 686-98.

[7] Killingsworth, M.R. (1983) Labor Supply. Cambridge, New York: Cambridge University Press.

[8] Krugman, P. (2000) Technology, Trade and Factor Prices. Journal of International Economics, 50, 51-71.

[9] Kydland, F.E. and E.C.Prescott (1996) The Computational Experiment: An Econometric Tool. Journal of Economic Perspectives, 10, 69-71.

[10] Leamer, E. (1998) In Search of Stolper-Samuelson Linkages between International Trade and Lower Wages. In ed. S. M. Collins Imports, Exports, and the American Worker. Washington, D.C.: Brookings Institution.

[11] Murphy, K.M., W.C.Riddell, and P.M.Romer (1998) Wages, Skills, and Technology in the United States and Canada. NBER working paper no. 6638.

[12] Shoven, J.B. and J.Whalley (1992) Applying General Equilibrium. Cambridge: Cambridge University Press. 
[13] Slaughter, M. (1999) Globalization and Wages: A Tale of Two Perspectives. World Economy, 22, 609-29.

[14] Sims, C.A. (1996) Macroeconomics and Methodology. Journal of Economic Perspectives, 10, 105-07.

[15] Stern, R.M., J.Francis, and B.Schumacher (1976) Price Elasticies in International Trade: An Annotated Bibliography. London: Macmillan (for the Trade Policy Research Center).

[16] Piggott, J. and J.Whalley (1985) New Development in Applied General Equilibrium Analysis. Cambridge: Cambridge University Press. 